OPEN ACCESS

Edited by:

Luigia Cristino,

Institute of Biomolecular Chemistry

(ICB), Italy

Reviewed by:

Dan P. Covey,

University of Maryland, Baltimore,

United States

Jeffrey G. Edwards,

Brigham Young University,

United States

*Correspondence:

Marco Pistis

mpisti@@unica.it

Received: 29 July 2020 Accepted: 16 September 2020 Published: 23 December 2020

Citation:

Sagheddu C, Torres $L H$,

Marcourakis T and Pistis M (2020) Endocannabinoid-Like Lipid

Neuromodulators in the Regulation of

Dopamine Signaling: Relevance for

Drug Addiction.

Front. Synaptic Neurosci. 12:588660.

doi: 10.3389/fnsyn.2020.588660

\section{Endocannabinoid-Like Lipid Neuromodulators in the Regulation of Dopamine Signaling: Relevance for Drug Addiction}

\author{
Claudia Sagheddu ${ }^{1}$, Larissa Helena Torres ${ }^{2}$, Tania Marcourakis ${ }^{3}$ and Marco Pistis ${ }^{1,4 *}$ \\ ${ }^{1}$ Department of Biomedical Sciences, Division of Neuroscience and Clinical Pharmacology, University of Cagliari, Cagliari, \\ Italy, ${ }^{2}$ Department of Food and Drugs, School of Pharmaceutical Sciences, Federal University of Alfenas, Alfenas, Brazil, \\ ${ }^{3}$ Department of Clinical and Toxicological Analysis, School of Pharmaceutical Sciences, University of São Paulo, São Paulo, \\ Brazil, ${ }^{4}$ Neuroscience Institute, National Research Council of Italy (CNR), Section of Cagliari, Cagliari, Italy
}

The family of lipid neuromodulators has been rapidly growing, as the use of different -omics techniques led to the discovery of a large number of naturally occurring $\mathrm{N}$-acylethanolamines (NAEs) and $\mathrm{N}$-acyl amino acids belonging to the complex lipid signaling system termed endocannabinoidome. These molecules exert a variety of biological activities in the central nervous system, as they modulate physiological processes in neurons and glial cells and are involved in the pathophysiology of neurological and psychiatric disorders. Their effects on dopamine cells have attracted attention, as dysfunctions of dopamine systems characterize a range of psychiatric disorders, i.e., schizophrenia and substance use disorders (SUD). While canonical endocannabinoids are known to regulate excitatory and inhibitory synaptic inputs impinging on dopamine cells and modulate several dopamine-mediated behaviors, such as reward and addiction, the effects of other lipid neuromodulators are far less clear. Here, we review the emerging role of endocannabinoid-like neuromodulators in dopamine signaling, with a focus on non-cannabinoid $\mathrm{N}$-acylethanolamines and their receptors. Mounting evidence suggests that these neuromodulators contribute to modulate synaptic transmission in dopamine regions and might represent a target for novel medications in alcohol and nicotine use disorder.

Keywords: $\mathrm{N}$-acylethanolamines, endocannabinoids, dopamine neurons, peroxisome proliferator-activated receptors- $\alpha$, nicotine, alcohol

\section{INTRODUCTION}

One of the most fascinating fields in contemporary neuroscience is the emergence of lipids as signaling molecules, with a multitude of compounds recognized as mediators of communication within and between neurons (Piomelli et al., 2007). Among lipid neuromodulators, research in the last two decades has been focusing on synthesis, cellular effects, and catabolism of 
TABLE 1 | Representative bioactive neural lipids, their cellular receptors, and their cellular effects on dopamine cells.

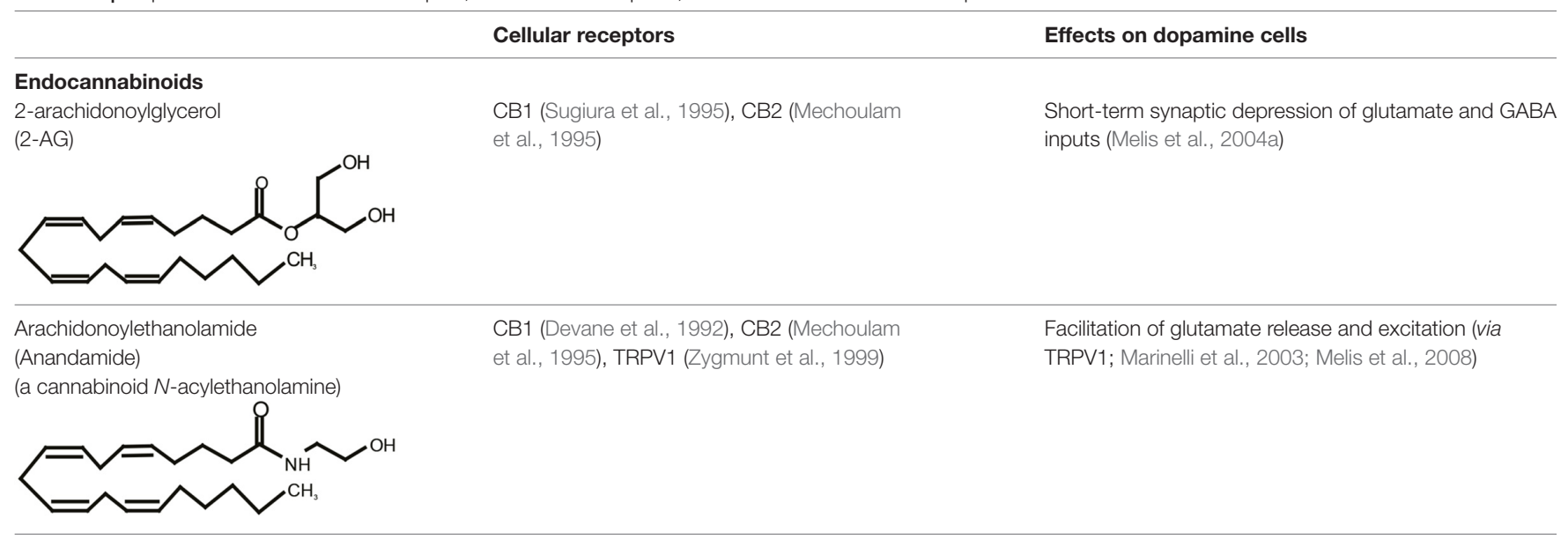

\section{Non-cannabinoid}

$\mathrm{N}$-acylethanolamines

Oleoylethanolamide PPAR $\alpha$ (Fu et al., 2003)

Phosphorylation and negative modulation of $\beta^{*}$-nAChRs

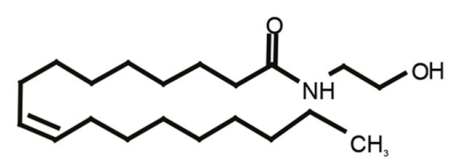

Palmitoylethanolamide

PPAR $\alpha$ (Lo Verme et al., 2005)

(Melis et al., 2008)

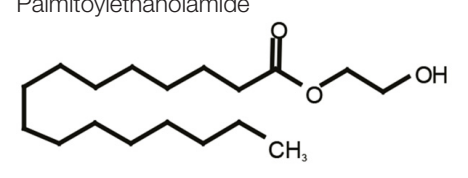

$N$-acyl amino acids

Oleoylglycine

PPAR $\alpha$ (Takao et al., 2015; Donvito et al., 2019)

Unknown

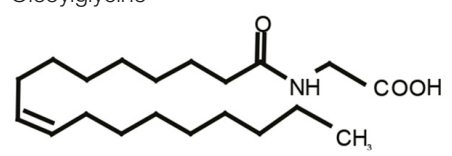

See text for abbreviations.

endogenous cannabinoids (eCBs) and their $\mathrm{CB} 1$ and $\mathrm{CB} 2$ cannabinoid receptors. The first characterized eCB, $\mathrm{N}$-arachidonoylethanolamide (anandamide, AEA; Devane et al., 1992; Table 1), is one member of the $N$-acylethanolamines' (NAEs) family, also termed fatty acid ethanolamides. NAEs differ in the length and saturation of the hydrocarbon chain and their receptor affinity (Schmid et al., 1990; Hansen et al., 2000). Besides AEA, the saturated palmitoylethanolamide (PEA) and the monounsaturated oleoylethanolamide (OEA) have attracted attention due to their biological effects in the brain and periphery (Table 1). $N$-acyl amino acids are another related family of lipid signaling molecules in which an amino acid is covalently linked by an amide bond to the acyl moiety of a long-chain fatty acid. Among $N$-acyl amino acids, $N$-acyl glycines (particularly $N$-arachidonylglycine and $N$-oleoylglycine) are emerging as an intriguing class of neuromodulators, although largely uncharacterized so far (Bradshaw et al., 2009; Burstein, 2018; Battista et al., 2019; Table 1).
Among NAEs, the cannabinoid agonist AEA binds to $\mathrm{CB} 1$ and $\mathrm{CB} 2$ receptors and transient receptor potential vanilloid type 1 (TRPV1) at physiologically relevant concentrations, the others display an affinity for peroxisome proliferator-activated receptor- $\alpha$ (PPAR $\alpha$; Lo Verme et al., 2005; Hansen, 2010; Petrosino et al., 2010; Pistis and Muntoni, 2017), G proteincoupled receptors such as GPR55 (Baker et al., 2006) and GPR119, and TRPV1 (Piomelli, 2013). $N$-acyl amino acids are less characterized; however, evidence suggests a role for GPR18, GPR55, and GPR92, and PPAR $\alpha$ in mediating some of the actions of $N$-oleoylglycine (Burstein, 2018; Donvito et al., 2019), which is one of the most studied among these molecules.

Although several of these molecules were known for decades, physiological activities of NAEs or $N$-acyl amino acids in the CNS and their role in neurological and psychiatric disorders, ranging from substance use disorder, neurodegenerative diseases, epilepsy, and mood disorders (Pistis and Melis, 2010; Melis and Pistis, 2014; Scherma et al., 2016; Pistis and Muntoni, 2017) has been characterized only relatively recently. 


\section{$N$-ACYLETHANOLAMINES AND N-ACYL AMINO ACIDS: SYNTHESIS AND CATABOLISM}

Both AEA and other non-cannabinoid NAEs share both biosynthetic and catabolic pathways. Unlike typical neurotransmitters, their levels are regulated on-demand by enzymes responsible for their synthesis and degradation (Ueda et al., 2010a; Rahman et al., 2014) and not by vesicular release. They are synthesized from membrane-derived $\mathrm{N}$ acylphosphatidylethanolamines (NAPEs; Hansen et al., 2000; Okamoto et al., 2004; Hansen, 2010; Ueda et al., 2010b; Rahman et al., 2014). The first step is the generation of the corresponding NAPE by a $\mathrm{Ca}^{2+}$-dependent $\mathrm{N}$-acyltransferase (NAT; Hansen et al., 2000; Hansen and Diep, 2009); NAPE is then hydrolyzed by NAPE-hydrolyzing phospholipase D (NAPE-PLD) with the generation of NAEs (Rahman et al., 2014; Figure 1).

Very little is known about the biosynthesis of $N$-acyl amino acids, except for $\mathrm{N}$-acyl glycines, where it is hypothesized that glycine is directly condensed with the free fatty acid or CoenzymeA derivative acyl moiety by cytochrome $\mathrm{C}$ or glycine NAT-like 2 and 3 enzymes (Huang et al., 2001; McCue et al., 2008; Waluk et al., 2010; see Burstein, 2018; Battista et al., 2019; for comprehensive reviews of $N$-acyl amino acids).

When catabolized, NAEs and $N$-acyl amino acids are hydrolyzed to free fatty acids and ethanolamine or amino acids (Cravatt et al., 1996; Deutsch et al., 2002; Battista et al., 2019), respectively (Figure 1). This hydrolysis is catalyzed mainly by two major intracellular enzymes, although alternative pathways have been described (Bornheim et al., 1993; Hampson et al., 1995; Ueda et al., 1995; Yu et al., 1997; Kozak et al., 2002). The first enzyme to be characterized is the fatty acid amide hydrolase (FAAH; Cravatt et al., 1996). FAAH hydrolyzes all NAEs and several $N$-acyl amino acids with high efficiency, and it is expressed in many different tissues and cell types, including in the brain. The second major enzyme is the NAE-hydrolyzing acid amidase (NAAA; Tsuboi et al., 2005), which displays a significant preference for unsaturated NAEs such as PEA (Tsuboi et al., 2007). NAAA displays lower expression in the brain, yet significant CNS effects are obtained with selective inhibitors (Sagheddu et al., 2019), suggesting that despite low expression levels, this enzyme exerts physiologicallyrelevant actions by controlling brain levels of NAEs.

Stimuli triggering NAEs' synthesis vary between AEA and other NAEs. Endocannabinoids like AEA and 2-arachidonoylglycerol (2-AG) are synthesized following activation of metabotropic glutamate, muscarinic, or dopamine D2 receptors (Melis et al., 2004a,b; Kano et al., 2009). Besides the activation of metabotropic receptors, both AEA, 2-AG, and non-cannabinoid NAEs synthesis is initiated by a rise in intracellular $\mathrm{Ca}^{2+}$ (Luchicchi and Pistis, 2012; Melis et al., $2013 \mathrm{~b})$. The reason for this similarity is presumed to be the $\mathrm{Ca}^{2+}$-dependency of the NAT enzyme. In experimental settings, the contribution of specific lipid neuromodulators can be disentangled with pharmacological tools, i.e., selective antagonists at their cellular receptors. Interestingly, both the canonical eCB signaling mediated by $\mathrm{AEA} / 2-\mathrm{AG}$ and the non-canonical OEA/PEA signaling have been characterized in dopamine neurons. However, it is still not clear whether these two separate signaling systems coexist in the same cell. As they are activated by different stimuli, they might fulfill different physiological functions. This scenario is consistent with the idea that NAE signaling displays exquisite anatomical and functional specificity. For example, activation of glutamate afferents in dopamine cells induces synthesis of 2-AG that, via $\mathrm{CB} 1$ receptors, dampens glutamate release (Melis et al., 2004a). On the other hand, acetylcholine release activates the OEA/PEA signaling (see below; Melis et al., 2010). Thus, both 2-AG and OEA/PEA signaling converge to reduce dopamine cell excitability, contributing to diminishing cellular overdrive induced by excitatory afferents. The functional relevance of these two distinct yet parallel systems needs to be fully understood.

The subcellular localization of NAPE-PLD in the brain is indicative of the possible functional significance of NAEs in the CNS (Cristino et al., 2008; Egertová et al., 2008; Nyilas et al., 2008; Suárez et al., 2008; Reguero et al., 2014; Merrill et al., 2015), as NAPE-PLD mRNA and immunoreactivity are detected both presynaptically and postsynaptically, but with a preferential distribution in postsynaptic dendrites (Reguero et al., 2014). The preferential postsynaptic localization of NAPE-PLD and NAEs affinity to nuclear receptors (see below) indicates that they may act as autocrine or paracrine signals at receptors expressed in the same or neighboring cells.

\section{$N$-ACYLETHANOLAMINE RECEPTORS: PEROXISOME PROLIFERATOR-ACTIVATED RECEPTOR- $\alpha$ (PPAR $\alpha)$}

PEA, OEA, and $N$-oleoylglycine targets have been identified as the PPAR, and specifically the $\alpha$-isoform (PPAR $\alpha)$. Very little is known about the functional relevance of $N$-acyl amino acids and their receptors such as GPR18, GPR55, or GPR92; this topic is discussed in Burstein (2018) and Battista et al. (2019).

In the brain, considerable evidence suggests that NAEs display activity through PPAR $\alpha$, receptors ubiquitously expressed in the CNS by neurons and glial cells (Braissant et al., 1996; Auboeuf et al., 1997; Mandard et al., 2004; Moreno et al., 2004; GalanRodriguez et al., 2009; Fidaleo et al., 2014).

PPARs belong to the large superfamily of transcription factors, composed of three isotypes: $\operatorname{PPAR} \alpha, \operatorname{PPAR} \gamma$ and PPAR $\beta / \delta$ (Germain et al., 2006). The large ligand-binding site of PPARs can accommodate a variety of diverse lipophilic endogenous ligands and synthetic agonists, including fibrates, clinically approved for decades for the treatment of hypertriglyceridemia. Hence, PPAR $\alpha$ is a transcriptional regulator of genes involved in peroxisomal and mitochondrial $\beta$-oxidation, and fatty acid transport (Xu et al., 2002). PPAR $\alpha$ is also engaged in the anti-inflammatory response, as it negatively regulates pro-inflammatory pathways and signals involved in the acute phase response in models of systemic inflammation 


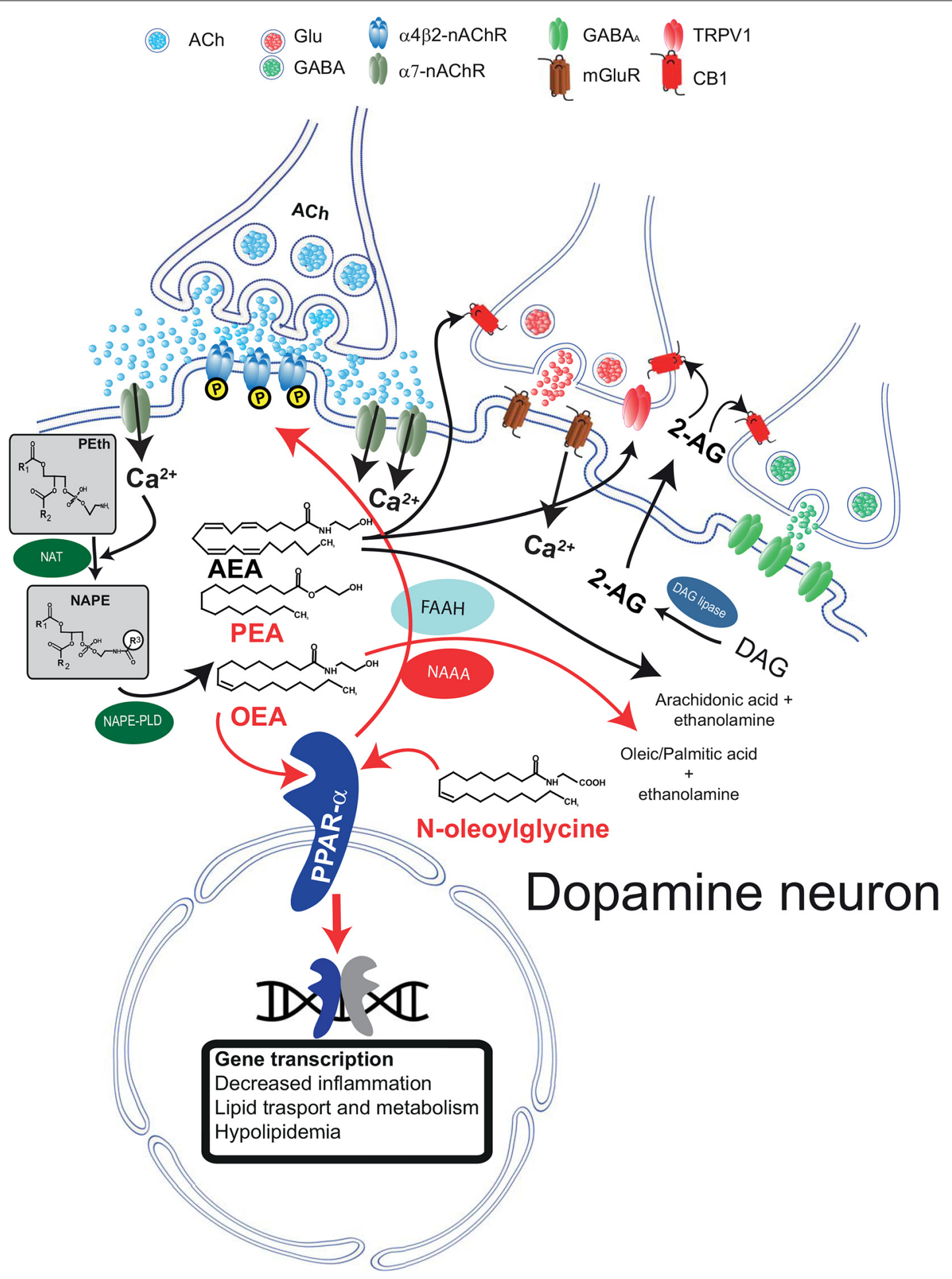

FIGURE 1 | Schematic diagram illustrating the biosynthetic and catabolic pathways for $\mathrm{N}$-acylethanolamine (NAE) and canonical endocannabinoid formation and catabolism, and their cellular mechanisms of actions through their receptors. Phosphatidylethanolamine (Peth) is converted into $\mathrm{N}$-acyl-phosphatidylethanolamine (NAPE) by $\mathrm{N}$-acyltransferase (NAT). $\mathrm{Ca}^{2+}$ entry mediated by $\alpha 7$-nAChRs activates NAEs synthesis through the $\mathrm{Ca}^{2+}$ dependent NAT. The resulting NAPE is hydrolyzed by NAPE-PLD to the corresponding NAEs anandamide (AEA), oleoyl ethanolamide (OEA), and palmitoylethanolamide (PEA). Activation of PPAR $\alpha$ by NAEs results in genomic effects (gene transcription) and in non-genomic actions, such as activation of a tyrosine kinase and phosphorylation of $\beta 2 * n A C h R s$ (i.e., a4ß2). Fatty acid amide hydrolase (FAAH) and NAE-hydrolyzing acid amidase (NAAA) are the major inactivating enzymes for OEA, PEA, and AEA and convert them in ethanolamine and corresponding fatty acids (oleic, palmitic, and arachidonic acids, respectively). NAAA preferentially hydrolyzes PEA. N-oleoyl glycine is one 
FIGURE 1 | Continued

member of the $\mathrm{N}$-acyl amino acid family and is known to activate PPAR $\alpha$. The figure illustrates that $A E A$ and 2-arachidonoylglycerol (2-AG) are produced on demand by NAPE-PLD and DAG lipase, respectively. Raises in intracellular $\mathrm{Ca}^{2+}$ can be induced, as in the example, by activation of metabotropic glutamate receptors (mGluR). 2-AG and AEA bind to presynaptic CB1 receptors expressed on GABA and glutamate terminals and depress neurotransmitter release. AEA also activates TRPV1 receptors located on presynaptic glutamatergic terminals. Abbreviations: NAPE-PLD, N-acyl phosphatidylethanolamine phospholipase D; DAG, diacylglycerol; MAG, monoacylglycerol; FAAH, fatty acid amide hydrolase; Glu, glutamate; CB1, cannabinoid type-1 receptor; TRPV1, transient receptor potential vanilloid type-1; PPAR $\alpha$, peroxisome proliferator-activated receptor type- $\alpha$; nAChRs, nicotinic acetylcholine receptors. This figure is adapted, with permission, from Melis and Pistis (2012) and Pistis and Muntoni (2017).

(Berger and Moller, 2002; Gervois et al., 2004; Moreno et al., 2004; Glass and Ogawa, 2006; Bensinger and Tontonoz, 2008).

\section{PPAR $\alpha$ AND DOPAMINE CELLS}

The anatomical and functional segregation between cannabinoid and non-cannabinoid NAEs in their cellular effects is evident in dopamine cells, where these two signaling systems have been characterized. Dopamine cells synthesize and release eCBs following activation of metabotropic receptors, membrane depolarization, and $\mathrm{Ca}^{2+}$ entry (Melis et al., 2004a,b). Released eCBs bind to presynaptic $\mathrm{CB} 1$ receptors expressed by GABA and glutamate terminals (Melis et al., 2004b, 2013a, 2014; Pistis et al., 2004; Figure 1). The functional relevance of eCB signaling is reviewed elsewhere (Melis and Pistis, 2007, 2012; Melis et al., 2012). Here, it suffices to say that eCBs sculpt short- and long-term forms of synaptic plasticity and fine-tune firing activity of dopamine cells, specifically in tasks where these neurons are engaged, such as reward and motivation.

A different scenario is emerging when NAEs are concerned. In dopamine cells, NAE synthesis is triggered by enhanced nicotinic cholinergic transmission, and the switch was identified as the low-affinity extrasynaptic $\alpha 7$ nicotinic acetylcholine receptor ( $\alpha 7-n$ AChRs; Jones, 2004; Yang et al., 2009; Figure 1). The interpretation for this finding is that this receptor, expressed in sites distant from cholinergic axon terminals (Jones, 2004), is a sensor for an intense cholinergic drive, being activated by acetylcholine (Yang et al., 2009) spilled over from cholinergic synapses impinging onto dopamine cells. $\alpha 7-n A C h R s$ are permeable to $\mathrm{Ca}^{2+}$ ions, and their activation by acetylcholine or exogenous ligands (i.e., nicotine) evokes an increase in $\mathrm{Ca}^{2+}$ permeability and a rise in intracellular $\mathrm{Ca}^{2+}$, which is necessary for the activity of the $\mathrm{Ca}^{2+}$-dependent NAT isoform (Ogura et al., 2016; Hussain et al., 2018). The result is a rise in levels of PEA and OEA, which, differently from eCBs, bind to intracellular receptors within the dopamine cell, acting as autocrine-like signals (Melis et al., 2013b; Figure 1) in a fashion similar to other neuromodulators, such as neurotrophic factors (Herrmann and Broihier, 2018). Other laboratories have confirmed the interaction between $\alpha 7-n A C h R s$ and PPAR $\alpha$ in different settings: Donvito et al.
(2017) observed that the antinociceptive effects of $\alpha 7-n A C h R$ agonists were mediated by a rise in PEA and activation of PPAR $\alpha$ and Jackson et al. (2017) confirmed that PPAR $\alpha$ is involved in the effects mediated by $\alpha 7-n A C h R$ agonists in nicotine dependence.

These effects have the potential to regulate synaptic functions. Our studies show that $\operatorname{PPAR} \alpha$ activation in VTA dopamine cells triggers, via endogenous hydrogen peroxide and consequent activation of tyrosine kinase(s) (Melis et al., 2008, 2010), phosphorylation of the $\beta 2$ subunits of the nAChRs (Melis et al., 2013b). Phosphorylation of $\mathrm{nAChR}$ subunits is an efficient way to regulate receptor functions by inducing a faster desensitization rate or a downregulation via internalization (Huganir and Greengard, 1990). Cholinergic inputs control firing rate and burst firing of midbrain dopamine cells via nAChRs (MameliEngvall et al., 2006), thus the functional regulation of $\beta 2$ subunits, that together with $\alpha 4$ are the main nAChR subunits expressed by VTA DA neurons (Champtiaux et al., 2003), might prove useful in nicotine addiction (see below) dopamine-related neurological or psychiatric disorders.

While modulation of $\mathrm{nAChRs}$ by PPAR $\alpha$ is one of the likely mechanisms by which these nuclear receptors acutely control dopaminergic transmission, we must take into account that genomic effects might also be highly relevant, e.g., anti-inflammatory effects. This is particularly important in psychiatric and neurological disorders when altered synaptic transmission and neuroinflammation interact to generate pathological phenotypes.

As non-cannabinoid NAEs are engaged by dopamine cells as an autocrine-like signal through PPAR $\alpha$ to regulate afferent projections and their own pattern of activity, it is not surprising that these lipid neuromodulators might play a major role in substance use disorders (SUD).

An extensive literature substantiates the role of the dopamine system in addiction and SUD. Dopamine facilitates the development of long-lasting forms of synaptic adaptations that determine the effectiveness of reward and reward predictors to control subsequent seeking behavior (Wise and Robble, 2020). Among several aspects of dopamine function related to addiction, the phasic firing of dopamine neurons sculpts learning processes, particularly when learning is associated with rewarding stimuli or its opposite, aversion (Wise and Robble, 2020).

Evidence is accumulating that metabolic enzymes and receptors of these eCB-like signals might be a target for medications in SUD, and specifically alcoholism or nicotine dependence. In contrast, evidence linking them to psychostimulant or opioid use disorders is still very limited.

\section{ROLE OF NAEs AND PPAR $\alpha$ IN ALCOHOL USE DISORDER}

It is well established that the eCB system in dopamine regions contributes to the motivation to consume alcohol. Evidence derives, among others, from the observation that the innate extent of susceptibility to alcohol use disorders (AUD) depends on increased eCB levels within mesolimbic dopamine regions 
(Basavarajappa et al., 2006; Sagheddu and Melis, 2015), and that administration of $\mathrm{CB} 1$ receptor antagonists reduces alcohol drinking in animal models of alcoholism (Colombo et al., 1998). Consistently, alcohol self-administration is controlled by CB1 receptors in the VTA-NAc circuit of alcohol-preferring rats (Malinen and Hyytia, 2008), and Sardinian alcohol-preferring rats show enhanced eCB-mediated synaptic plasticity in the VTA when compared with Sardinian non preferring rats as controls (Melis et al., 2014).

Evidence is recently accumulating on non-cannabinoid NAEs' contribution to AUD (Orio et al., 2019). OEA has been shown to reduce behavioral expression of withdrawal, such as manifest signs of distress and alcohol-seeking (Bilbao et al., 2016). In rats, this is associated with the molecular effects of OEA, which counteracts alcohol-induced glial and neuronal alterations in brain regions processing drug reward (Rivera et al., 2019). Being antioxidant, anti-inflammatory, and neuroprotective, OEA, and PEA are considered molecules with therapeutic potential in comorbid disorders, including depression and anxiety in AUD (Pistis and Muntoni, 2017).

The role of NAEs in alcohol dependence has been extensively explored by studying the catabolic enzyme FAAH, both in rodents and humans. Several studies stress out the importance of FAAH genetic variants (Zhou et al., 2016; Sloan et al., 2018), or its enzymatic functionality as a factor contributing to the severity of the pathology. Recently, a PET scan study for a FAAH radiotracer was conducted in the brain of AUD patients during early abstinence. It showed transiently reduced FAAH levels, while its substrates AEA, OEA, and $N$-docosahexaenoyl ethanolamide (DEA) were elevated in the plasma (Best et al., 2020). Low FAAH levels are related to drinking behaviors and increased preference for alcohol, as demonstrated in several studies using animal models with genetic deletions (Basavarajappa et al., 2006; Blednov et al., 2006; Vinod et al., 2008; Pavón et al., 2018); or following pharmacological manipulation (Zhou et al., 2017).

$\operatorname{PPAR} \alpha$ is upstream of diverse genes that are modulated by ethanol or involved in ethanol-induced effects (Ferguson et al., 2014). Preclinical studies showed that modulation of PPAR $\alpha$ by the synthetic agonist fenofibrate reduced motivational and reinforcing properties of ethanol, as measured by voluntary drinking in mice (Ferguson et al., 2014; Blednov et al., 2016) and rats (Karahanian et al., 2015); and corroborated by the self-administration paradigm in rats (Haile and Kosten, 2017). Considering that fibrates are approved for medical conditions, these studies suggest that regulation of $\operatorname{PPAR} \alpha$ deserves further clinical investigation in AUD, as recently detailed elsewhere (Karahanian et al., 2015; Matheson and Le Foll, 2020). Nonetheless, there are no pending clinical trials to date. An interesting pharmacological approach takes advantage of combining drugs acting at PPAR $\alpha$ and other receptors. PPAR $\alpha / \gamma$ dual agonists have proven to reduce alcohol consumption in both mice (Blednov et al., 2015) and rats (Alen et al., 2018). Dual $\mathrm{CB} 1$ antagonist/PPAR $\alpha$ agonist reduced voluntary ethanol intake and self-administration in rat models of AUD (Alen et al., 2018), arising a promising step forward to the safe pharmacological manipulation of the eCB system.

\section{ROLE OF NAEs AND PPAR $\alpha$ IN ADDICTION: NICOTINE DEPENDENCE}

Tobacco use is associated with high morbidity and mortality, it being the most preventable cause of death in the world (World Health Organization, 2019). Nicotine, the main psychoactive component in tobacco, is one of the most addictive substances (Picciotto and Mineur, 2014) and exerts its effects through nAChRs.

Both tobacco smoke and nicotine can affect the eCB system. Tobacco smoke alters FAAH, NAPE-PLD, and MAGL levels in the striatum (Torres et al., 2019), while nicotine modifies eCB signaling according to the administration protocol. For instance, nicotine self-administration decreased OEA and increased AEA and 2-AG levels, while nicotine infusion, as well as mecamylamine-induced nicotine withdrawal, only increased 2-AG levels (Buczynski et al., 2013; Saravia et al., 2017). A critical role for 2-AG was also demonstrated in nicotine reinforcement (Buczynski et al., 2016) and in nicotine-induced dopamine release (Cheer et al., 2007). The overlap of nAChRs and the receptors of the $\mathrm{eCB}$ system in brain areas critical to nicotine effects, such as the mesolimbic system, shows that the eCB system plays an important role in nicotine dependence (Gamaleddin et al., 2015).

The involvement of the eCB system in nicotine dependence was demonstrated by the effect of FAAH inhibitors. FAAH inhibitors suppress many reward-related effects of nicotine in rats and non-human primates, such as nicotine self-administration and reinstatement of nicotine seeking (Scherma et al., 2008; Forget et al., 2009; Gamaleddin et al., 2015; Justinova et al., 2015); nicotine-induced excitation of dopamine neurons in the VTA (Melis et al., 2008), and dopamine release (Scherma et al., 2008). Importantly, the involvement of both $\mathrm{CB} 1$ and $\mathrm{PPAR} \alpha$ receptors was reported.

Besides the effect of the major eCBs, there is increasing evidence of the involvement of PEA and OEA in nicotine addiction, as they have a crucial role as endogenous modulators of cholinergic transmission (Melis et al., 2013b). Moreover, they also inhibit nicotine addictive behaviors, changing dopamine cell excitability. All these actions are due to the activation of PPAR $\alpha$, rather than CB1 receptor (Melis et al., 2008), being dependent on PEA and OEA synthesis as a result of activation of the cholinergic system, via $\alpha 7-n A C h R s$, and subsequent increase of intracellular $\mathrm{Ca}^{2+}$ (Melis et al., 2013b; Figure 1). Using in vivo and in vitro strategies, Melis et al. (2010) confirmed that the $\beta 2$ subunit is crucial for PPAR $\alpha$ effects, as re-expression of $\beta 2$ receptors in VTA dopamine cells in $\beta 2$ knockout mice was sufficient to rescue PPAR $\alpha$ effects. Consistently, $N$-oleoyl glycine was shown by Donvito et al. (2019) to counteract several effects related to nicotine reward and dependence, including the withdrawal syndrome, with a PPAR $\alpha$-dependent mechanism. It is not known if this $N$-acyl amino acid is synthesized in dopamine cells and acts as an endogenous neuromodulator in a similar fashion of other NAEs with a dopamine moiety such as $N$-arachidonoyldopamine or N-oleoyldopamine (Ferreira et al., 2009; Sergeeva et al., 2017), so its role in the modulation in dopamine-mediated behaviors such as SUD are not clear yet. 
Based on the mechanisms described, the suppression of nicotine-induced responses of dopamine neurons by PPAR $\alpha$ agonists raised the interest on these ligands as a promising strategy to prevent nicotine relapse (Melis and Pistis, 2014; Matheson and Le Foll, 2020). To date, two clinical studies investigated the effects of PPAR $\alpha$ agonists-gemfibrozil and fenofibrate-in smoking cessation, as a drug repositioning strategy. The authors did not observe beneficial effects of gemfibrozil or fenofibrate in treatment-seeking smokers (Perkins et al., 2016; Gendy et al., 2018). It must be pointed out that these disappointing results might be due to the low agonist potency and limited brain permeability in humans of clinically approved fibrates, which might result in low brain concentrations of these drugs, insufficient to achieve an optimal PPAR $\alpha$ activation in the CNS. Indeed, doses of fenofibrate higher than those tested in the studies mentioned above were beneficial in a form of epilepsy induced by a gain of function of nAChRs, the sleep-related hyper motor epilepsy (SHE; formerly termed nocturnal frontal lobe epilepsy, NFLE; Puligheddu et al., 2017).

A way to circumvent the limited brain permeability of fibrates is to increase brain levels of endogenous PPAR $\alpha$ agonists, such as PEA and OEA. The recent development of brain-permeant selective NAAA inhibitors offers the advantage to modulate levels of PEA and OEA selectively, and not AEA, therefore concurrently limiting psychiatric side effects due to eCB-CB1 alteration. Similar to direct PPAR $\alpha$ agonists, also NAAA inhibitors display potential as anti-smoking medications, as they block nicotine-induced excitation of dopamine cells, dopamine elevations in the nucleus accumbens, and conditioned place preference in a PPAR $\alpha$-dependent manner (Sagheddu et al., 2019).

\section{CONCLUDING REMARKS}

The expanded eCB system, the "endocannabinoidome," is a hotbed for a large number of lipid signaling molecules, enzymes, and receptors and represents a Pandora's box for drug discovery (Cristino et al., 2020).

This review article summarizes evidence suggesting that NAE/PPAR $\alpha$ signaling shows promise as a target in the treatment of SUD, particularly alcohol and nicotine use disorder. A parsimonious unifying hypothesis for this effect

\section{REFERENCES}

Alen, F., Decara, J., Brunori, G., You, Z.-B., Bühler, K.-M., López-Moreno, J. A., et al. (2018). PPAR $\alpha / C B 1$ receptor dual ligands as a novel therapy for alcohol use disorder: evaluation of a novel oleic acid conjugate in preclinical rat models. Biochem. Pharmacol. 157, 235-243. doi: 10.1016/j.bcp.2018. 09.008

Auboeuf, D., Rieusset, J., Fajas, L., Vallier, P., Frering, V., Riou, J. P., et al. (1997). Tissue distribution and quantification of the expression of mRNAs of peroxisome proliferator-activated receptors and liver $\mathrm{X}$ receptor- $\alpha$ in humans: no alteration in adipose tissue of obese and NIDDM patients. Diabetes 46, 1319-1327. doi: 10.2337/diab.46.8.1319

Baker, D., Pryce, G., Davies, W. L., and Hiley, C. R. (2006). In silico patent searching reveals a new cannabinoid receptor. Trends Pharmacol. Sci. 27, 1-4. doi: 10.1016/j.tips.2005.11.003 is NAE/PPAR $\alpha$ 's ability to modulate dopamine cell activity by specifically dampening stress-evoked excitatory drive from cholinergic afferents on VTA dopamine cells. Hence, a heightened cholinergic transmission has long been postulated to contribute to detrimental effects induced by stress, such as depression (Janowsky et al., 1972) and drug addiction (Morel et al., 2018; Shinohara et al., 2019). Consistently, selective inhibition of cholinergic neurons in the laterodorsal tegmentum, which provides a major cholinergic input to dopamine cells, prevents stress-induced cellular adaptations within VTA dopamine cells and the appearance of anhedonia and social withdrawal (Fernandez et al., 2018). Additionally, PPAR $\alpha$ activation attenuates effects induced by stress (Scheggi et al., 2016; Ni et al., 2018; Song et al., 2018; Locci and Pinna, 2019), corroborating the idea that the interplay between stress, cholinergic inputs, dopamine neurons, and PPAR $\alpha$ signaling might play a pivotal role in the potential favorable effects of NAEs in SUD.

SUD represents an unmet clinical need, with drugs currently in use that show limited efficacy or untoward side effects. Indeed, results reported for members of the NAE and $\mathrm{N}$-acyl amino acid family suggest that analogs of these lipid neuromodulators could become potential drug candidates.

\section{AUTHOR CONTRIBUTIONS}

CS, LT, TM, and MP wrote the manuscript. All authors contributed to the article and approved the submitted version.

\section{FUNDING}

This work was supported by Ministero dell'Istruzione, dell'Universitá e della Ricerca; "FSC 2014-2020-Patto per lo Sviluppo della Regione Sardegna, Legge Regionale n. 7 del 7 agosto 2007 (Bando 2017)" and by "Progetti di Rilevante Interesse Nazionale" (Regione Autonoma della Sardegna; PRIN) 2017 (2017YH3SXK).

\section{ACKNOWLEDGMENTS}

We wish to thank Dr. Barbara Tuveri and Mrs. Marta Tuveri for their skillful assistance.

Basavarajappa, B. S., Yalamanchili, R., Cravatt, B. F., Cooper, T. B., and Hungund, B. L. (2006). Increased ethanol consumption and preference and decreased ethanol sensitivity in female FAAH knockout mice. Neuropharmacology 50, 834-844. doi: 10.1016/j.neuropharm.2005.12.005

Battista, N., Bari, M., and Bisogno, T. (2019). N-acyl amino acids: metabolism, molecular targets and role in biological processes. Biomolecules 9:822. doi: 10.3390/biom 9120822

Bensinger, S. J., and Tontonoz, P. (2008). Integration of metabolism and inflammation by lipid-activated nuclear receptors. Nature 454, 470-477. doi: $10.1038 /$ nature07202

Berger, J., and Moller, D. E. (2002). The mechanisms of action of PPARs. Annu. Rev. Med. 53, 409-435. doi: 10.1146/annurev.med.53.082901.104018

Best, L. M., Williams, B., Le Foll, B., Mansouri, E., Bazinet, R. P., Lin, L. et al. (2020). Lower brain fatty acid amide hydrolase in treatment-seeking patients with alcohol use disorder: a positron emission tomography study with 
[C-11]CURB. Neuropsychopharmacology 45, 1289-1296. doi: 10.1038/s41386020-0606-2

Bilbao, A., Serrano, A., Cippitelli, A., Pavón, F. J., Giuffrida, A., Suárez, J., et al. (2016). Role of the satiety factor oleoylethanolamide in alcoholism. Addict. Biol. 21, 859-872. doi: 10.1111/adb.12276

Blednov, Y. A., Benavidez, J. M., Black, M., Ferguson, L. B., Schoenhard, G. L., Goate, A. M., et al. (2015). Peroxisome proliferator-activated receptors $\alpha$ and $\gamma$ are linked with alcohol consumption in mice and withdrawal and dependence in humans. Alcohol. Clin. Exp. Res. 39, 136-145. doi: 10.1111/acer.12610

Blednov, Y. A., Black, M., Benavidez, J. M., Stamatakis, E. E., and Harris, R. A. (2016). PPAR Agonists: I. Role of receptor subunits in alcohol consumption in male and female mice. Alcohol. Clin. Exp. Res. 40, 553-562. doi: 10.1111/acer. 12976

Blednov, Y. A., Cravatt, B. F., Boehm, S. L., Walker, D., and Harris, R. A. (2006). Role of endocannabinoids in alcohol consumption and intoxication: studies of mice lacking fatty acid amide hydrolase. Neuropsychopharmacology 32, 1570-1582. doi: 10.1038/sj.npp.1301274

Bornheim, L. M., Kim, K. Y., Chen, B., and Correia, M. A. (1993). The effect of cannabidiol on mouse hepatic microsomal cytochrome P450-dependent anandamide metabolism. Biochem. Biophys. Res. Commun. 197, 740-746. doi: 10.1006/bbrc. 1993.2541

Bradshaw, H. B., Rimmerman, N., Hu, S. S., Burstein, S., and Walker, J. M. (2009). Novel endogenous $\mathrm{N}$-acyl glycines identification and characterization. Vitam. Horm. 81, 191-205. doi: 10.1016/S0083-6729(09)81008-X

Braissant, O., Foufelle, F., Scotto, C., Dauca, M., and Wahli, W. (1996). Differential expression of peroxisome proliferator-activated receptors (PPARs): tissue distribution of PPAR- $\alpha,-\beta$ and $-\gamma$ in the adult rat. Endocrinology $137,354-366$. doi: 10.1210/endo.137.1.8536636

Buczynski, M. W., Herman, M. A., Hsu, K. L., Natividad, L. A., Irimia, C., Polis, I. Y., et al. (2016). Diacylglycerol lipase disinhibits VTA dopamine neurons during chronic nicotine exposure. Proc. Natl. Acad. Sci. U S A 113, 1086-1091. doi: 10.1073/pnas.1522672113

Buczynski, M. W., Polis, I. Y., and Parsons, L. H. (2013). The volitional nature of nicotine exposure alters anandamide and oleoylethanolamide levels in the ventral tegmental area. Neuropsychopharmacology 38, 574-584. doi: 10.1038/npp.2012.210

Burstein, S. H. (2018). $N$-acyl amino acids (elmiric acids): endogenous signaling molecules with therapeutic potential. Mol. Pharmacol. 93, 228-238. doi: 10.1124/mol.117.110841

Champtiaux, N., Gotti, C., Cordero-Erausquin, M., David, D. J., Przybylski, C., Léna, C., et al. (2003). Subunit composition of functional nicotinic receptors in dopaminergic neurons investigated with knock-out mice. J. Neurosci. 23, 7820-7829. doi: 10.1523/JNEUROSCI.23-21-07820.2003

Cheer, J. F., Wassum, K. M., Sombers, L. A., Heien, M. L., Ariansen, J. L., Aragona, B. J., et al. (2007). Phasic dopamine release evoked by abused substances requires cannabinoid receptor activation. J. Neurosci. 27, 791-795. doi: 10.1523/JNEUROSCI.4152-06.2007

Colombo, G., Agabio, R., Fa, M., Guano, L., Lobina, C., Loche, A., et al. (1998). Reduction of voluntary ethanol intake in ethanol-preferring sP rats by the cannabinoid antagonist SR-141716. Alcohol Alcohol. 33, 126-130. doi: 10.1093/oxfordjournals.alcalc.a008368

Cravatt, B. F., Giang, D. K., Mayfield, S. P., Boger, D. L., Lerner, R. A., and Gilula, N. B. (1996). Molecular characterization of an enzyme that degrades neuromodulatory fatty-acid amides. Nature 384, 83-87. doi: 10.1038/384083a0

Cristino, L., Bisogno, T., and Di Marzo, V. (2020). Cannabinoids and the expanded endocannabinoid system in neurological disorders. Nat. Rev. Neurol. 16, 9-29. doi: 10.1038/s41582-019-0284-z

Cristino, L., Starowicz, K., De Petrocellis, L., Morishita, J., Ueda, N., Guglielmotti, V., et al. (2008). Immunohistochemical localization of anabolic and catabolic enzymes for anandamide and other putative endovanilloids in the hippocampus and cerebellar cortex of the mouse brain. Neuroscience 151, 955-968. doi: 10.1016/j.neuroscience.2007.11.047

Deutsch, D. G., Ueda, N., and Yamamoto, S. (2002). The fatty acid amide hydrolase (FAAH). Prostaglandins Leukot. Essent. Fatty Acids 66, 201-210. doi: 10.1054 /plef.2001.0358

Devane, W. A., Hanus, L., Breuer, A., Pertwee, R. G., Stevenson, L. A., Griffin, G., et al. (1992). Isolation and structure of a brain constituent that binds to the cannabinoid receptor. Science 258, 1946-1949. doi: 10.1126/science.1470919
Donvito, G., Bagdas, D., Toma, W., Rahimpour, E., Jackson, A., Meade, J. A., et al. (2017). The interaction between $\alpha 7$ nicotinic acetylcholine receptor and nuclear peroxisome proliferator-activated receptor- $\alpha$ represents a new antinociceptive signaling pathway in mice. Exp. Neurol. 295, 194-201. doi: 10.1016/j.expneurol. 2017.06.014

Donvito, G., Piscitelli, F., Muldoon, P., Jackson, A., Vitale, R. M., D’Aniello, E., et al. (2019). $N$-oleoyl-glycine reduces nicotine reward and withdrawal in mice. Neuropharmacology 148, 320-331. doi: 10.1016/j.neuropharm.2018.03.020

Egertová, M., Simon, G. M., Cravatt, B. F., and Elphick, M. R. (2008). Localization of $N$-acyl phosphatidylethanolamine phospholipase D (NAPEPLD) expression in mouse brain: a new perspective on $N$-acylethanolamines as neural signaling molecules. J. Comp. Neurol. 506, 604-615. doi: 10.1002/cne. 21568

Ferguson, L. B., Most, D., Blednov, Y. A., and Harris, R. A. (2014). PPAR agonists regulate brain gene expression: relationship to their effects on ethanol consumption. Neuropharmacology 86, 397-407. doi: 10.1016/j.neuropharm. 2014.06.024

Fernandez, S. P., Broussot, L., Marti, F., Contesse, T., Mouska, X., SoizaReilly, M., et al. (2018). Mesopontine cholinergic inputs to midbrain dopamine neurons drive stress-induced depressive-like behaviors. Nat. Commun. 9:4449. doi: 10.1038/s41467-018-06809-7

Ferreira, S. G., Lomaglio, T., Avelino, A., Cruz, F., Oliveira, C. R., Cunha, R. A., et al. (2009). $N$-acyldopamines control striatal input terminals via novel ligand-gated cation channels. Neuropharmacology 56, 676-683. doi: 10.1016/j. neuropharm.2008.12.001

Fidaleo, M., Fanelli, F., Ceru, M. P., and Moreno, S. (2014). Neuroprotective properties of peroxisome proliferator-activated receptor $\alpha(\operatorname{PPAR} \alpha)$ and its lipid ligands. Curr. Med. Chem. 21, 2803-2821. doi: 10.2174/0929867321666140303143455

Forget, B., Coen, K. M., and Le Foll, B. (2009). Inhibition of fatty acid amide hydrolase reduces reinstatement of nicotine seeking but not break point for nicotine self-administration-comparison with $\mathrm{CB}(1)$ receptor blockade. Psychopharmacology 205, 613-624. doi: 10.1007/s00213-009-1569-5

Fu, J., Gaetani, S., Oveisi, F., Lo Verme, J., Serrano, A., Rodriguez De Fonseca, F., et al. (2003). Oleylethanolamide regulates feeding and body weight through activation of the nuclear receptor PPAR- $\alpha$. Nature 425, 90-93. doi: $10.1038 /$ nature 01921

Galan-Rodriguez, B., Suarez, J., Gonzalez-Aparicio, R., Bermudez-Silva, F. J., Maldonado, R., Robledo, P., et al. (2009). Oleoylethanolamide exerts partial and dose-dependent neuroprotection of substantia nigra dopamine neurons. Neuropharmacology 56, 653-664. doi: 10.1016/j.neuropharm.2008.11.006

Gamaleddin, I. H., Trigo, J. M., Gueye, A. B., Zvonok, A., Makriyannis, A., Goldberg, S. R., et al. (2015). Role of the endogenous cannabinoid system in nicotine addiction: novel insights. Front. Psychiatry 6:41. doi: 10.3389/fpsyt. 2015.00041

Gendy, M. N. S., Di Ciano, P., Kowalczyk, W. J., Barrett, S. P., George, T. P., Heishman, S., et al. (2018). Testing the PPAR hypothesis of tobacco use disorder in humans: a randomized trial of the impact of gemfibrozil (a partial PPAR $\alpha$ agonist) in smokers. PLoS One 13:e0201512. doi: 10.1371/journal.pone. 0201512

Germain, P., Staels, B., Dacquet, C., Spedding, M., and Laudet, V. (2006). Overview of nomenclature of nuclear receptors. Pharmacol. Rev. 58, 685-704. doi: 10.1124/pr.58.4.2

Gervois, P., Kleemann, R., Pilon, A., Percevault, F., Koenig, W., Staels, B., et al. (2004). Global suppression of IL-6-induced acute phase response gene expression after chronic in vivo treatment with the peroxisome proliferatoractivated receptor- $\alpha$ activator fenofibrate. J. Biol. Chem. 279, 16154-16160. doi: $10.1074 /$ jbc.M400346200

Glass, C. K., and Ogawa, S. (2006). Combinatorial roles of nuclear receptors in inflammation and immunity. Nat. Rev. Immunol. 6, 44-55. doi: $10.1038 /$ nri1748

Haile, C. N., and Kosten, T. A. (2017). The peroxisome proliferator-activated receptor $\alpha$ agonist fenofibrate attenuates alcohol self-administration in rats. Drug Alcohol Depend. 171:e81. doi: 10.1016/j.neuropharm.2017.01.007

Hampson, A. J., Hill, W. A., Zan-Phillips, M., Makriyannis, A., Leung, E., Eglen, R. M., et al. (1995). Anandamide hydroxylation by brain lipoxygenase: metabolite structures and potencies at the cannabinoid receptor. Biochim. Biophys. Acta 1259, 173-179. doi: 10.1016/0005-2760(95)00157-8 
Hansen, H. S. (2010). Palmitoylethanolamide and other anandamide congeners. Proposed role in the diseased brain. Exp. Neurol. 224, 48-55. doi: 10.1016/j. expneurol.2010.03.022

Hansen, H. S., and Diep, T. A. (2009). $N$-acylethanolamines, anandamide and food intake. Biochem. Pharmacol. 78, 553-560. doi: 10.1016/j.bcp.2009.04.024

Hansen, H. S., Moesgaard, B., Hansen, H. H., and Petersen, G. (2000). $\mathrm{N}$-acylethanolamines and precursor phospholipids-relation to cell injury. Chem. Phys. Lipids 108, 135-150. doi: 10.1016/s0009-3084(00)00192-4

Herrmann, K. A., and Broihier, H. T. (2018). What neurons tell themselves: autocrine signals play essential roles in neuronal development and function. Curr. Opin. Neurobiol. 51, 70-79. doi: 10.1016/j.conb.2018.03.002

Huang, S. M., Bisogno, T., Petros, T. J., Chang, S. Y., Zavitsanos, P. A., Zipkin, R. E., et al. (2001). Identification of a new class of molecules, the arachidonyl amino acids and characterization of one member that inhibits pain. J. Biol. Chem. 276, 42639-42644. doi: 10.1074/jbc.M107351200

Huganir, R. L., and Greengard, P. (1990). Regulation of neurotransmitter receptor desensitization by protein phosphorylation. Neuron 5, 555-567. doi: 10.1016/0896-6273(90)90211-w

Hussain, Z., Uyama, T., Kawai, K., Binte Mustafiz, S. S., Tsuboi, K., Araki, N., et al. (2018). Phosphatidylserine-stimulated production of $\mathrm{N}$-acylphosphatidylethanolamines by $\mathrm{Ca}^{2+}$-dependent $N$-acyltransferase. Biochim. Biophys. Acta Mol. Cell Biol. Lipids 1863, 493-502. doi: 10.1016/j.bbalip.2018. 02.002

Jackson, A., Bagdas, D., Muldoon, P. P., Lichtman, A. H., Carroll, F. I., Greenwald, M., et al. (2017). In vivo interactions between $\alpha 7$ nicotinic acetylcholine receptor and nuclear peroxisome proliferator-activated receptor$\alpha$ : implication for nicotine dependence. Neuropharmacology 118, 38-45. doi: 10.1016/j.neuropharm.2017.03.005

Janowsky, D. S., el-Yousef, M. K., Davis, J. M., and Sekerke, H. J. (1972). A cholinergic-adrenergic hypothesis of mania and depression. Lancet 2, 632-635. doi: 10.1016/s0140-6736(72)93021-8

Jones, I. W. (2004). Precise localization of 7 nicotinic acetylcholine receptors on glutamatergic axon terminals in the rat ventral tegmental area. J. Neurosci. 24, 11244-11252. doi: 10.1523/JNEUROSCI.3009-04.2004

Justinova, Z., Panlilio, L. V., Moreno-Sanz, G., Redhi, G. H., Auber, A., Secci, M. E., et al. (2015). Effects of fatty acid amide hydrolase (FAAH) inhibitors in non-human primate models of nicotine reward and relapse. Neuropsychopharmacology 40, 2185-2197. doi: 10.1038/npp.2015.62

Kano, M., Ohno-Shosaku, T., Hashimotodani, Y., Uchigashima, M., and Watanabe, M. (2009). Endocannabinoid-mediated control of synaptic transmission. Physiol. Rev. 89, 309-380. doi: 10.1152/physrev.00019.2008

Karahanian, E., Rivera-Meza, M., Quintanilla, M. E., Muñoz, D., Fernández, K., and Israel, Y. (2015). PPAR $\alpha$ agonists reduce alcohol drinking: do they act in the brain or in the liver? Alcohol Alcohol. 50, 717-718. doi: 10.1093/alcalc/agv060

Kozak, K. R., Crews, B. C., Morrow, J. D., Wang, L. H., Ma, Y. H., Weinander, R., et al. (2002). Metabolism of the endocannabinoids, 2-arachidonylglycerol and anandamide, into prostaglandin, thromboxane and prostacyclin glycerol esters and ethanolamides. J. Biol. Chem. 277, 44877-44885. doi: 10.1074/jbc. M206788200

Lo Verme, J., Fu, J., Astarita, G., La Rana, G., Russo, R., Calignano, A., et al. (2005). The nuclear receptor peroxisome proliferator-activated receptor- $\alpha$ mediates the anti-inflammatory actions of palmitoylethanolamide. Mol. Pharmacol. 67, 15-19. doi: 10.1124/mol.104.006353

Locci, A., and Pinna, G. (2019). Stimulation of peroxisome proliferatoractivated receptor- $\alpha$ by $N$-palmitoylethanolamine engages allopregnanolone biosynthesis to modulate emotional behavior. Biol. Psychiatry 85, 1036-1045. doi: 10.1016/j.biopsych.2019.02.006

Luchicchi, A., and Pistis, M. (2012). Anandamide and 2-arachidonoylglycerol: pharmacological properties, functional features and emerging specificities of the two major endocannabinoids. Mol. Neurobiol. 46, 374-392. doi: 10.1007/s12035-012-8299-0

Malinen, H., and Hyytia, P. (2008). Ethanol self-administration is regulated by $\mathrm{CB} 1$ receptors in the nucleus accumbens and ventral tegmental area in alcoholpreferring AA rats. Alcohol. Clin. Exp. Res. 32, 1976-1983. doi: 10.1111/j.15300277.2008.00786.x

Mameli-Engvall, M., Evrard, A., Pons, S., Maskos, U., Svensson, T. H., Changeux, J. P., et al. (2006). Hierarchical control of dopamine neuron-firing patterns by nicotinic receptors. Neuron 50, 911-921. doi: 10.1016/j.neuron. 2006.05.007

Mandard, S., Muller, M., and Kersten, S. (2004). Peroxisome proliferator-activated receptor $\alpha$ target genes. Cell. Mol. Life Sci. 61, 393-416. doi: 10.1007/s00018003-3216-3

Marinelli, S., Di Marzo, V., Berretta, N., Matias, I., Maccarrone, M., Bernardi, G., et al. (2003). Presynaptic facilitation of glutamatergic synapses to dopaminergic neurons of the rat substantia nigra by endogenous stimulation of vanilloid receptors. J. Neurosci. 23, 3136-3144. doi: 10.1523/JNEUROSCI.23-08-031 36.2003

Matheson, J., and Le Foll, B. (2020). Therapeutic potential of peroxisome proliferator-activated receptor (PPAR) agonists in substance use disorders: a synthesis of preclinical and human evidence. Cells 9:1196. doi: 10.3390/cells9051196

McCue, J. M., Driscoll, W. J., and Mueller, G. P. (2008). Cytochrome c catalyzes the in vitro synthesis of arachidonoyl glycine. Biochem. Biophys. Res. Commun. 365, 322-327. doi: 10.1016/j.bbrc.2007.10.175

Mechoulam, R., Ben-Shabat, S., Hanus, L., Ligumsky, M., Kaminski, N. E., Schatz, A. R., et al. (1995). Identification of an endogenous 2-monoglyceride, present in canine gut, that binds to cannabinoid receptors. Biochem. Pharmacol. 50, 83-90. doi: 10.1016/0006-2952(95)00109-d

Melis, M., Carta, S., Fattore, L., Tolu, S., Yasar, S., Goldberg, S. R., et al. (2010). Peroxisome proliferator-activated receptors- $\alpha$ modulate dopamine cell activity through nicotinic receptors. Biol. Psychiatry 68, 256-264. doi: 10.1016/j. biopsych.2010.04.016

Melis, M., De Felice, M., Lecca, S., Fattore, L., and Pistis, M. (2013a). Sex-specific tonic 2-arachidonoylglycerol signaling at inhibitory inputs onto dopamine neurons of Lister Hooded rats. Front. Integr. Neurosci. 7:93. doi: 10.3389/fnint. 2013.00093

Melis, M., Scheggi, S., Carta, G., Madeddu, C., Lecca, S., Luchicchi, A., et al. (2013b). PPAR $\alpha$ regulates cholinergic-driven activity of midbrain dopamine neurons via a novel mechanism involving $\alpha 7$ nicotinic acetylcholine receptors. J. Neurosci. 33, 6203-6211. doi: 10.1523/JNEUROSCI.464712.2013

Melis, M., and Pistis, M. (2007). Endocannabinoid signaling in midbrain dopamine neurons: more than physiology? Curr. Neuropharmacol. 5, 268-277. doi: $10.2174 / 157015907782793612$

Melis, M., and Pistis, M. (2012). Hub and switches: endocannabinoid signalling in midbrain dopamine neurons. Philos. Trans. R. Soc. Lond. B. Biol. Sci. 367, 3276-3285. doi: 10.1098/rstb.2011.0383

Melis, M., and Pistis, M. (2014). Targeting the interaction between fatty acid ethanolamides and nicotinic receptors: therapeutic perspectives. Pharmacol. Res. 86, 42-49. doi: 10.1016/j.phrs.2014.03.009

Melis, M., Muntoni, A. L., and Pistis, M. (2012). Endocannabinoids and the processing of value-related signals. Front. Pharmacol. 3:7. doi: 10.3389/fphar. 2012.00007

Melis, M., Perra, S., Muntoni, A. L., Pillolla, G., Lutz, B., Marsicano, G., et al. (2004a). Prefrontal cortex stimulation induces 2-arachidonoyl-glycerolmediated suppression of excitation in dopamine neurons. J. Neurosci. 24, 10707-10715. doi: 10.1523/JNEUROSCI.3502-04.2004

Melis, M., Pistis, M., Perra, S., Muntoni, A. L., Pillolla, G., and Gessa, G. L. (2004b). Endocannabinoids mediate presynaptic inhibition of glutamatergic transmission in rat ventral tegmental area dopamine neurons through activation of CB1 receptors. J. Neurosci. 24, 53-62. doi: 10.1523/JNEUROSCI. 4503-03.2004

Melis, M., Pillolla, G., Luchicchi, A., Muntoni, A. L., Yasar, S., Goldberg, S. R. et al. (2008). Endogenous fatty acid ethanolamides suppress nicotine-induced activation of mesolimbic dopamine neurons through nuclear receptors. J. Neurosci. 28, 13985-13994. doi: 10.1523/JNEUROSCI.3221-08.2008

Melis, M., Sagheddu, C., De Felice, M., Casti, A., Madeddu, C., Spiga, S., et al. (2014). Enhanced endocannabinoid-mediated modulation of rostromedial tegmental nucleus drive onto dopamine neurons in Sardinian alcoholpreferring rats. J. Neurosci. 34, 12716-12724. doi: 10.1523/JNEUROSCI.184414.2014

Merrill, C. B., Friend, L. N., Newton, S. T., Hopkins, Z. H., and Edwards, J. G. (2015). Ventral tegmental area dopamine and GABA neurons: physiological properties and expression of mRNA for endocannabinoid biosynthetic elements. Sci. Rep. 5:16176. doi: 10.1038/srep16176 
Morel, C., Fernandez, S. P., Pantouli, F., Meye, F. J., Marti, F., Tolu, S., et al. (2018). Nicotinic receptors mediate stress-nicotine detrimental interplay via dopamine cells' activity. Mol. Psychiatry 23, 1597-1605. doi: 10.1038/mp.2017.145

Moreno, S., Farioli-Vecchioli, S., and Cerù, M. P. (2004). Immunolocalization of peroxisome proliferator-activated receptors and retinoid $\mathrm{X}$ receptors in the adult rat CNS. Neuroscience 123, 131-145. doi: 10.1016/j.neuroscience.2003. 08.064

Ni, Y.-F., Wang, H., Gu, Q.-Y., Wang, F.-Y., Wang, Y.-J., Wang, J.-L., et al. (2018). Gemfibrozil has antidepressant effects in mice: involvement of the hippocampal brain-derived neurotrophic factor system. J. Psychopharmacol. 32, 469-481. doi: 10.1177/0269881118762072

Nyilas, R., Dudok, B., Urbán, G. M., Mackie, K., Watanabe, M., Cravatt, B. F., et al. (2008). Enzymatic machinery for endocannabinoid biosynthesis associated with calcium stores in glutamatergic axon terminals. J. Neurosci. 28, 1058-1063. doi: 10.1523/JNEUROSCI.5102-07.2008

Ogura, Y., Parsons, W. H., Kamat, S. S., and Cravatt, B. F. (2016). A calciumdependent acyltransferase that produces $N$-acyl phosphatidylethanolamines. Nat. Chem. Biol. 12, 669-671. doi: 10.1038/nchembio.2127

Okamoto, Y., Morishita, J., Tsuboi, K., Tonai, T., and Ueda, N. (2004). Molecular characterization of a phospholipase D generating anandamide and its congeners. J. Biol. Chem. 279, 5298-5305. doi: 10.1074/jbc.M3066 42200

Orio, L., Alen, F., Pavón, F. J., Serrano, A., and García-Bueno, B. (2019). Oleoylethanolamide, Neuroinflammation and Alcohol Abuse. Front. Mol. Neurosci. 11:490. doi: 10.3389/fnmol.2018.00490

Pavón, F. J., Serrano, A., Stouffer, D. G., Polis, I., Roberto, M., Cravatt, B. F., et al. (2018). Ethanol-induced alterations in endocannabinoids and relevant neurotransmitters in the nucleus accumbens of fatty acid amide hydrolase knockout mice. Addict. Biol. 24, 1204-1215. doi: 10.1111/adb.12695

Perkins, K. A., Karelitz, J. L., Michael, V. C., Fromuth, M., Conklin, C. A., Chengappa, K. N., et al. (2016). Initial evaluation of fenofibrate for efficacy in aiding smoking abstinence. Nicotine Tob. Res. 18, 74-78. doi: $10.1093 / \mathrm{ntr} / \mathrm{ntv} 085$

Petrosino, S., Iuvone, T., and Di Marzo, V. (2010). N-palmitoyl-ethanolamine: biochemistry and new therapeutic opportunities. Biochimie 92, 724-727. doi: 10.1016/j.biochi.2010.01.006

Picciotto, M. R., and Mineur, Y. S. (2014). Molecules and circuits involved in nicotine addiction: the many faces of smoking. Neuropharmacology 76, 545-553. doi: 10.1016/j.neuropharm.2013.04.028

Piomelli, D. (2013). A fatty gut feeling. Trends Endocrinol. Metab. 24, 332-341. doi: 10.1016/j.tem.2013.03.001

Piomelli, D., Astarita, G., and Rapaka, R. (2007). A neuroscientist's guide to lipidomics. Nat. Rev. Neurosci. 8, 743-754. doi: 10.1038/nrn2233

Pistis, M., and Melis, M. (2010). From surface to nuclear receptors: the endocannabinoid family extends its assets. Curr. Med. Chem. 17, 1450-1467. doi: 10.2174/092986710790980014

Pistis, M., and Muntoni, A. L. (2017). "Roles of $N$-acylethanolamines in brain functions and neuropsychiatric diseases," in Endocannabinoids and Lipid Mediators in Brain Functions, ed. M. Melis (Cham: Springer International Publishing), 319-346.

Pistis, M., Perra, S., Pillolla, G., Melis, M., Gessa, G. L., and Muntoni, A. L. (2004). Cannabinoids modulate neuronal firing in the rat basolateral amygdala: evidence for CB1- and non-CB1-mediated actions. Neuropharmacology 46, 115-125. doi: 10.1016/j.neuropharm.2003.08.003

Puligheddu, M., Melis, M., Pillolla, G., Milioli, G., Parrino, L., Terzano, G. M., et al. (2017). Rationale for an adjunctive therapy with fenofibrate in pharmacoresistant nocturnal frontal lobe epilepsy. Epilepsia 58, 1762-1770. doi: 10.1111/epi.13863

Rahman, I. A., Tsuboi, K., Uyama, T., and Ueda, N. (2014). New players in the fatty acyl ethanolamide metabolism. Pharmacol. Res. 86, 1-10. doi: 10.1016/j. phrs.2014.04.001

Reguero, L., Puente, N., Elezgarai, I., Ramos-Uriarte, A., Gerrikagoitia, I., BuenoLopez, J. L., et al. (2014). Subcellular localization of NAPE-PLD and DAGL$\alpha$ in the ventromedial nucleus of the hypothalamus by a preembedding immunogold method. Histochem. Cell Biol. 141, 543-550. doi: 10.1007/s00418013-1174-x

Rivera, P., Silva-Peña, D., Blanco, E., Vargas, A., Arrabal, S., Serrano, A., et al. (2019). Oleoylethanolamide restores alcohol-induced inhibition of neuronal proliferation and microglial activity in striatum. Neuropharmacology 146, 184-197. doi: 10.1016/j.neuropharm.2018.11.037

Sagheddu, C., and Melis, M. (2015). Individual differences and vulnerability to drug addiction: a focus on the endocannabinoid system. CNS Neurol. Disord Drug Targets 14, 502-517. doi: 10.2174/1871527314666150225143748

Sagheddu, C., Scherma, M., Congiu, M., Fadda, P., Carta, G., Banni, S., et al. (2019). Inhibition of $N$-acylethanolamine acid amidase reduces nicotineinduced dopamine activation and reward. Neuropharmacology 144, 327-336. doi: 10.1016/j.neuropharm.2018.11.013

Saravia, R., Flores, A., Plaza-Zabala, A., Busquets-Garcia, A., Pastor, A., de la Torre, R., et al. (2017). CB1 cannabinoid receptors mediate cognitive deficits and structural plasticity changes during nicotine withdrawal. Biol. Psychiatry 81, 625-634. doi: 10.1016/j.biopsych.2016.07.007

Scheggi, S., Melis, M., De Felice, M., Aroni, S., Muntoni, A. L., Pelliccia, T., et al. (2016). PPAR $\alpha$ modulation of mesolimbic dopamine transmission rescues depression-related behaviors. Neuropharmacology 110, 251-259. doi: 10.1016/j. neuropharm.2016.07.024

Scherma, M., Muntoni, A. L., Melis, M., Fattore, L., Fadda, P., Fratta, W., et al. (2016). Interactions between the endocannabinoid and nicotinic cholinergic systems: preclinical evidence and therapeutic perspectives. Psychopharmacology 233, 1765-1777. doi: 10.1007/s00213-015-4196-3

Scherma, M., Panlilio, L. V., Fadda, P., Fattore, L., Gamaleddin, I., Le Foll, B., et al. (2008). Inhibition of anandamide hydrolysis by URB597 reverses abuserelated behavioral and neurochemical effects of nicotine in rats. J. Pharmacol. Exp. Ther. 327, 482-490. doi: 10.1124/jpet.108.142224

Schmid, H. H., Schmid, P. C., and Natarajan, V. (1990). N-acylated glycerophospholipids and their derivatives. Prog. Lipid Res. 29, 1-43. doi: 10.1016/0163-7827(90)90004-5

Sergeeva, O. A., De Luca, R., Mazur, K., Chepkova, A. N., Haas, H. L., and Bauer, A. (2017). N-oleoyldopamine modulates activity of midbrain dopaminergic neurons through multiple mechanisms. Neuropharmacology 119, 111-122. doi: 10.1016/j.neuropharm.2017.04.011

Shinohara, F., Asaoka, Y., Kamii, H., Minami, M., and Kaneda, K. (2019). Stress augments the rewarding memory of cocaine via the activation of brainstemreward circuitry. Addict. Biol. 24, 509-521. doi: 10.1111/adb.12617

Sloan, M. E., Gowin, J. L., Yan, J., Schwandt, M. L., Spagnolo, P. A., Sun, H., et al. (2018). Severity of alcohol dependence is associated with the fatty acid amide hydrolase Pro129Thr missense variant. Addict. Biol. 23, 474-484. doi: $10.1111 /$ adb. 12491

Song, L., Wang, H., Wang, Y. J., Wang, J. L., Zhu, Q., Wu, F., et al. (2018). Hippocampal PPAR $\alpha$ is a novel therapeutic target for depression and mediates the antidepressant actions of fluoxetine in mice. Br. J. Pharmacol. 175, 2968-2987. doi: 10.1111/bph. 14346

Suárez, J., Bermúdez-Silva, F. J., Mackie, K., Ledent, C., Zimmer, A., Cravatt, B. F., et al. (2008). Immunohistochemical description of the endogenous cannabinoid system in the rat cerebellum and functionally related nuclei. J. Comp. Neurol. 509, 400-421. doi: 10.1002/cne.21774

Sugiura, T., Kondo, S., Sukagawa, A., Nakane, S., Shinoda, A., Itoh, K., et al. (1995). 2-Arachidonoylglycerol: a possible endogenous cannabinoid receptor ligand in brain. Biochem. Biophys. Res. Commun. 215, 89-97. doi: 10.1006/bbrc. 1995.2437

Takao, K., Noguchi, K., Hashimoto, Y., Shirahata, A., and Sugita, Y. (2015). Synthesis and evaluation of fatty acid amides on the $N$-oleoylethanolamide-like activation of peroxisome proliferator activated receptor $\alpha$. Chem. Pharm. Bull. 63, 278-285. doi: 10.1248/cpb.c14-00881

Torres, L. H., Balestrin, N. T., Spelta, L. E. W., Duro, S. O., Pistis, M., and Marcourakis, T. (2019). Exposure to tobacco smoke during the early postnatal period modifies receptors and enzymes of the endocannabinoid system in the brainstem and striatum in mice. Toxicol. Lett. 302, 35-41. doi: 10.1016/j.toxlet. 2018.12.002

Tsuboi, K., Sun, Y. X., Okamoto, Y., Araki, N., Tonai, T., and Ueda, N. (2005). Molecular characterization of $\mathrm{N}$-acylethanolamine-hydrolyzing acid amidase, a novel member of the choloylglycine hydrolase family with structural and functional similarity to acid ceramidase. J. Biol. Chem. 280, 11082-11092. doi: 10.1074/jbc.M413473200

Tsuboi, K., Takezaki, N., and Ueda, N. (2007). The N-acylethanolaminehydrolyzing acid amidase (NAAA). Chem. Biodivers. 4, 1914-1925. doi: 10.1002/cbdv.200790159 
Ueda, N., Tsuboi, K., and Uyama, T. (2010a). Enzymological studies on the biosynthesis of $N$-acylethanolamines. Biochim. Biophys. Acta 1801, 1274-1285. doi: 10.1016/j.bbalip.2010.08.010

Ueda, N., Tsuboi, K., and Uyama, T. (2010b). N-acylethanolamine metabolism with special reference to $N$-acylethanolamine-hydrolyzing acid amidase (NAAA). Prog. Lipid Res. 49, 299-315. doi: 10.1016/j.plipres.2010.02.003

Ueda, N., Yamamoto, K., Yamamoto, S., Tokunaga, T., Shirakawa, E., Shinkai, H., et al. (1995). Lipoxygenase-catalyzed oxygenation of arachidonylethanolamide, a cannabinoid receptor agonist. Biochim. Biophys. Acta 1254, 127-134. doi: 10.1016/0005-2760(94)00170-4

Vinod, K. Y., Sanguino, E., Yalamanchili, R., Manzanares, J., and Hungund, B. L. (2008). Manipulation of fatty acid amide hydrolase functional activity alters sensitivity and dependence to ethanol. J. Neurochem. 104, 233-243. doi: 10.1111/j.1471-4159.2007.04956.x

Waluk, D. P., Schultz, N., and Hunt, M. C. (2010). Identification of glycine $N$-acyltransferase-like 2 (GLYATL2) as a transferase that produces $N$-acyl glycines in humans. FASEB J. 24, 2795-2803. doi: 10.1096/fj.09-148551

Wise, R. A., and Robble, M. A. (2020). Dopamine and addiction. Annu. Rev. Psychol. 71, 79-106. doi: 10.1146/annurev-psych-010418103337

World Health Organization. (2019). Who Report on the Global Tobacco Epidemic. Geneva, Switzerland: World Health Organization.

Xu, J., Xiao, G., Trujillo, C., Chang, V., Blanco, L., Joseph, S. B., et al. (2002). Peroxisome proliferator-activated receptor $\alpha(\operatorname{PPAR} \alpha)$ influences substrate utilization for hepatic glucose production. J. Biol. Chem. 277, 50237-50244. doi: 10.1074/jbc.M201208200

Yang, K., Hu, J., Lucero, L., Liu, Q., Zheng, C., Zhen, X., et al. (2009). Distinctive nicotinic acetylcholine receptor functional phenotypes of rat ventral tegmental area dopaminergic neurons. J. Physiol. 587, 345-361. doi: 10.1113/jphysiol. 2008.162743

Yu, M., Ives, D., and Ramesha, C. S. (1997). Synthesis of prostaglandin E2 ethanolamide from anandamide by cyclooxygenase-2. J. Biol. Chem. 272, 21181-21186. doi: 10.1074/jbc.272.34.21181

Zhou, Y., Huang, T., Lee, F., and Kreek, M. J. (2016). Involvement of endocannabinoids in alcohol "binge" drinking: studies of mice with human fatty acid amide hydrolase genetic variation and after CB1 receptor antagonists. Alcohol. Clin. Exp. Res. 40, 467-473. doi: 10.1111/acer.12989

Zhou, Y., Schwartz, B. I., Giza, J., Gross, S. S., Lee, F. S., and Kreek, M. J. (2017). Blockade of alcohol escalation and "relapse" drinking by pharmacological FAAH inhibition in male and female C57BL/6J mice. Psychopharmacology 234, 2955-2970. doi: 10.1007/s00213-017-4691-9

Zygmunt, P. M., Petersson, J., Andersson, D. A., Chuang, H., Sorgard, M., Di Marzo, V., et al. (1999). Vanilloid receptors on sensory nerves mediate the vasodilator action of anandamide. Nature 400, 452-457. doi: 10.1038/22761

Conflict of Interest: The authors declare that the research was conducted in the absence of any commercial or financial relationships that could be construed as a potential conflict of interest.

Copyright (C) 2020 Sagheddu, Torres, Marcourakis and Pistis. This is an open-access article distributed under the terms of the Creative Commons Attribution License (CC BY). The use, distribution or reproduction in other forums is permitted, provided the original author(s) and the copyright owner(s) are credited and that the original publication in this journal is cited, in accordance with accepted academic practice. No use, distribution or reproduction is permitted which does not comply with these terms. 